Professor J. G. Murray and Mr. C. T. Howe gave encouragement and advice. Professor T. Nicol, Dr. B. Vernon-Roberts, and Dr. D. C. Quantock, of the department of anatomy, King's College, London, suggested the application of their technique using aggregated albumin prepared by the research department of Pfizer Ltd. The radioactive isotopes were handled by Mr. M. B. Clark. Dr. R. P. Knill-Jones advised on the statistical methods and provided conputer programmes to assist with the calculations.

\section{References}

Ashley, D. J. B. (1969). British fournal of Cancer, 23, 21.

Batchelor, J. R., and Chapman, B. A. (1965). Immunology, 9, 553

Bates, R. R. (1968). Fournal of the National Cancer Institute, 41, 559.

Baum, M. (1967). British fournal of Surgery, $\mathbf{5 4 , 2 2 9}$

Baum, M. (1967). British fournal of Surgery, $54,229$. et des ses Filiales, 151, 1326 .

Bradner, W. T., and Clarke, D. A. (1959). Cancer Research, 19, 673.

Dao, T. L., and Yogo, H. (1967). Cancer (Philadelphia), 20, 2020.

Draper, L. R. (1962). In Ionising Radiations and Immune Processes, ed. C. A. Leone, p. 221. New York, Gordon and Breach.

Fairley, G. H. (1969). British Medical fournal, 2, 467.

Field, J. R., Ershoff, B. H., Dolendo, E., and Mireles, A. (1967). Proceedings of the American Association for Cancer Research, 8, 17.

Graff, R. J., Lappé, M. A., and Snell, G. D. (1969). Transplantation, 7, 105. Green, H. N., Anthony, H. M., Baldwin, R. W., and Westrop, J. W. (1967). An Immunological Approach to Cancer. London, Butterworths.

Halpern, B. N., Stiffel, G., Biozzi, G., and Mouton, D. (1960). Comptes Rendus des Seances de la Societe de Biologie et des ses Filiales, 154, 1994.

Halpern, B. N.. Biozzi, G., Stiffel, C., and Mouton, D. (1966). Nature, 212, 853.
Kondo, T., and Moore, G. E. (1961), Cancer Research, 21, 1396.

Lancet, 1968, 1, 1298

Magarey, C. J. (1970). Thesis submitted to the University of Sydney for the Degree of Master of Surgery.

Magarey, C. J., and Baum, M. (1970). British fournal of Surgery, 57, 748.

Martin, D. S., I Iugmann, R. A., and Hayworth, P. (1961). Fournal of the American Medical Association, 178, 723.

Martin, D. S., Hayworth, P., Fugmann, R. A., English, R., and McNeill, H. W. (1964). Cancer Research, 24, 652.

Mathé, G. (1969). British Medical fournal, 4, 7.

Mirand, E. A., and Lasser, E. C. (1955). Experimental Medicine and Surgery, 13,234

Nicol, T. (1935). Transactions of the Royal Society of Edinburgh, 58, 449. Nicol, T., Helmy, I. D., and Abon-Zikry, A. (1952). British fournal of Surgery, 40, 166.

Nicol, T., and Vernon-Roberts, B. (1959). Journal of the Reticuloendothelial

Society, 2, 15.
Nicol, T., Bilbey, D. L. J., Charles, L. M., Cordingley, J. L., and VernonRoberts, B. (1964). Fournal of Endocrinology, 30, 277 .

Nicol, T., Vernon-Roberts, B., and Quantock, D. C. (1965). Journal of Endocrinology, 33, 365 .

Old, L. J., Benacerraf, B., Clarke, D. A., Carswell, E. A., and Stockert, E. (1961). Cancer Research, 21, 1281.

Old, L. J., and Boyse, E. A. (1964). Annual Review of Medicine, 15,167.

Reiner, J., and Southam, C. M. (1966). Nature, 210, 429.

Rosenau, W., and Moon, H. D. (1967). Cancer Research, 27, 1973.

Sokoloff, B., et al. (1961). Growth, 25, 249.

Thunold, S. (1967). Acta Pathologica et Microbiologica Scandinavica, 69, 521.

Treadwell, A. de G., Gardener, W. U., and Lawrence, J. H. (1943). Endocrinology, 32, 161 .

Weiss, D. W., Bonhag, R. S., and DeOme, K. B. (1961). Nature, 190, 889. Woodruff, M. F. A., and Boak, J. L. (1966). British Fournal of Cancer, 20, 345.

Yamaguchi, I., Takahashi, T., Narisawa, T., and Hiroki, T. (1965). Tohoku fournal of Experimental Medicine, 87, 338.

\title{
Evaluation of Silicone as an Artificial Lubricant in Osteoarthrotic Joints
}

\author{
V. WRIGHT, D. I. HASLOCK, D. DOWSON, P. C. SELLER, B. REEVES
}

British Medical fournal, 1971, 2, 370-373

\section{Summary}

Silicone 300 has been evaluated as an artificial lubricant in osteoarthrotic joints by means of a pilot study in five inpatients and a control trial of 25 outpatients with 40 osteoarthrotic knees. Sequential analysis showed a significant benefit from saline compared with silicone at one week follow-up and no significant difference at one month.

Measurement of stiffness with a knee arthrograph showed no difference in reduction of stiffness between the two substances. In a study of 18 rabbits there was no evidence that silicone was retained in the joint cavity for longer than 48 hours. There was a failure of clearance of iodinated serum albumin for as long as three to four days after the injection of silicone, suggesting some obstruction to lymphatic outflow. Experimentally produced cartilaginous defects did not heal quicker with the injection of silicone into the joint.

\footnotetext{
Bio-engineering Group for the Study of Human Joints, University of Leeds, Leeds LS2 9PJ

V. WRIGHT, M.D., F.R.C.P., Professor of Rheumatology

D. I. HASLOCK, M.B., CH.B., Registrar in Rheumatology

D. DOWSON, PH.D., F.I.MECH.E., Professor of Engineering, Fluid Mechanics, and Tribology

P. C. SELLER, M.SC., Research Student

Leeds Regional Hospital Board

B. REEVES, M.S., F.R.C.s., Consultant Orthopaedic Surgeon
}

\section{Introduction}

The nature of the lubrication process in human joints has undergone extensive studies in recent years. A number of workers have investigated the normal lubricating mechanism (McCutchen, 1959; Charnley, 1960; Barnett and Cobbold, 1962; Dintenfass, 1963; Tanner, 1966; Maroudas, 1967; Dowson et al., 1968), the way in which it fails in pathological conditions, and the possibility of producing an artificial lubricant for therapeutic use (Helal and Karadi, 1968; Nuki et al., 1969; Seller et al., 1969). We have previously suggested the following criteria for an artificial lubricant. It should behave in friction tests and on scanning electron microscopy like hyaluronic acid-protein complex. It should resist thermal, mechanical, and oxidative degradation. It should be tolerable within the joint space and be retained there. It should be cheap and easy to produce. However, other workers have reported the successful use of a silicone fluid in osteoarthrosis (Helal and Karadi, 1968). To evaluate silicone $300^{*}$ as an artificial lubricant a pilot study was conducted and a controlled trial was performed.

\section{Patients and Methods}

A pilot study of five inpatients with osteoarthrosis demonstrated clinically and radiologically in one or more knees was undertaken. The more severely affected knee in each patient was injected with silicone, the patients being assessed before injection and daily for one week thereafter. Long-term follow-up was continued in the outpatient department. The amount of pain was recorded on a rating scale $(0=$ none, $1=$ mild,

* Silicone of nominal viscosity 300 centistokes, grade F111, was supplied by I.C.I. 
$2=$ moderate, $3=$ severe, $4=$ unbearably severe). Subjective stiffness was also graded $0=$ none, $1=$ mild, $2=$ moderate, $3=$ severe, $4=$ immobile. The patient's overall progress was separately assessed by the patient and the physicians as nil, mild or marked deterioration, or mild or marked improvement.

Physical stiffness of the knees was recorded with a knee arthrograph shown in Fig. 1. This measured the resistance to passive movement of the knee when a sinusoidal motion was imposed (Goddard et al., 1969).

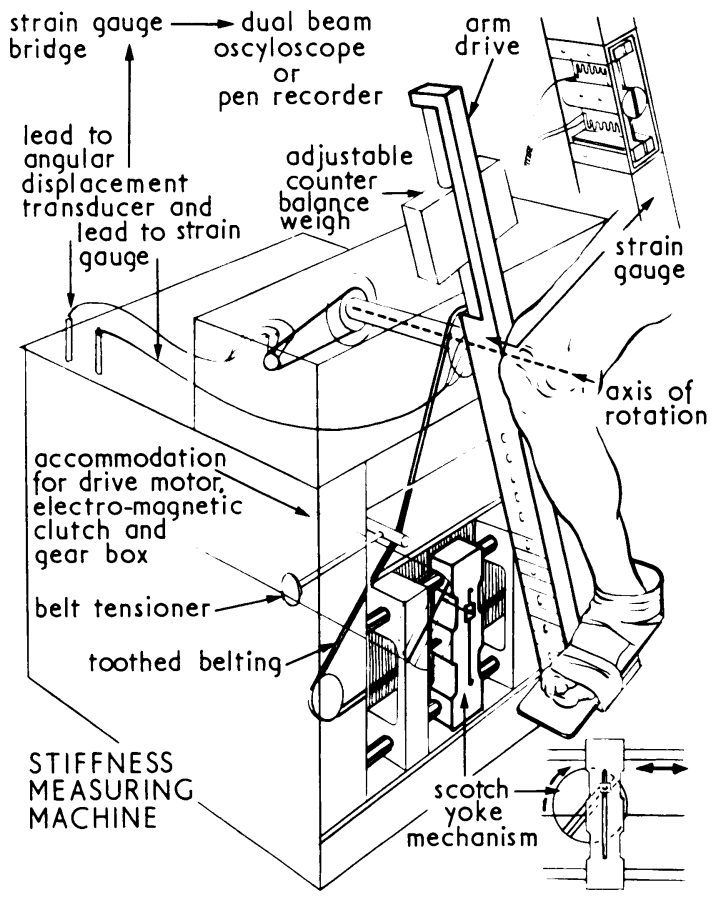

FIG. 1-Knee arthrograph.

Twenty-five outpatients with a total of 40 osteoarthrotic knees were included in a controlled trial. The efficacy of $10 \mathrm{ml}$ of silicone 300 was compared with that of $10 \mathrm{ml}$ of normal saline. As these two fluids are very different in their physical characteristics a normal double-blind technique could not be used. Fifteen pairs of knees were, therefore, paired internally-that is both knees in one patient-and five pairs externally-that is, one knee from each of two matched patients. Assessment of pain and stiffness was carried out before injection, and of pain, stiffness, and overall response one and four weeks after injection by one physician. The injections were carried out by the second physician, one knee of each pair being injected with silicone, the other with saline, in a random fashion. The assessments were, therefore, made with no knowledge by the patient or examining physician of the substance injected, and the results at each visit were recorded on a separate sheet which was not available at subsequent visits, since it has been shown that this may influence assessments (Jacobsen, 1965). Informed consent was obtained from all patients.

In $18 \mathrm{New}$ Zealand white rabbits weighing between 3.9 and $4.4 \mathrm{~kg}, 1.5 \mathrm{ml}$ of silicone 300 was injected intra-articularly; in each the clearance patterns of a 6-microcurie dose of radioactive sodium iodide ${ }^{131}$ I or iodinated human serum albumin had been established under standard experimental conditions in relation to the depth of anaesthesia and animal body and room temperatures. Preliminary experiments have shown that a maximum joint capacity without leakage of fluid into the bursa in relation to tibialis anterior in rabbits of this size is between 1.9 and $2.4 \mathrm{ml}$. The present volume was therefore taken to produce a maximum joint distension with a reasonable safety factor to avoid extravasation into the tibialis anterior bursa; this, being extremely large in extent, would be apt to produce fallacious results. The intrarticular pressures were also measured during the injection process, and it has also been shown that a rise in intra-articular pressure above $25 \mathrm{~mm}$ of mercury during the injection process is apt to open up the valve-like entrance to this bursa. In nine rabbits serial studies were made of sodium ${ }^{131}$ I clearance and iodated human serum albumin from the knee joint, compared with both the preinjection state and the contralateral knee. The animals were killed between 24 hours and four weeks postoperatively. In the other nine rabbits $2-\mathrm{mm}$ circular defects were produced in the lateral femoral condyle on both the experimental and the contralateral knee 24 hours before injecting the silicone 300 , and the animals were slaughtered at periods of up to six weeks after surgery.

\section{Results}

Pilot Study with Silicone.-The patients' mean pain score before injection and after injection was 3.2 and 2.4 respectively. There was no alteration in subjective stiffness. The patients' overall response to the procedure shows two distinct patterns. Three patients claimed dramatic improvement in the injected knee, while two felt that the procedure made no difference. The improvement was considered by the physicians to be marked in one patient and mild in the other two who claimed dramatic benefit. The maximum response was obtained in all cases within $\mathbf{4 8}$ hours of injection, and did not vary thereafter. In two patients, of whom one improved and one did not, a rise in temperature was observed clinically over the injected knee. In neither case was this noted by the patient. These results are summarized in the Table.

Silicone Trial. Pilot Study: Summary of Results

\begin{tabular}{|c|c|c|c|c|c|c|}
\hline \multirow[t]{2}{*}{ Patient } & \multicolumn{2}{|c|}{ Before Injection } & \multicolumn{2}{|c|}{ After Injection } & \multicolumn{2}{|c|}{ Overall Result } \\
\hline & Pain & Stiffness & Pain & Stiffness & Patient & Physician \\
\hline $\begin{array}{l}\ldots \\
\cdots \\
\cdots \\
\cdots\end{array}$ & $\begin{array}{l}3 \\
4 \\
4 \\
3 \\
2\end{array}$ & $\begin{array}{l}3 \\
1 \\
4 \\
2 \\
0\end{array}$ & $\begin{array}{l}3 \\
2 \\
3 \\
2 \\
2\end{array}$ & $\begin{array}{l}3 \\
2 \\
3 \\
2 \\
0\end{array}$ & $\begin{array}{r}0 \\
+2 \\
0 \\
+2 \\
+2\end{array}$ & $\begin{array}{r}0 \\
+2 \\
0 \\
+1 \\
+1\end{array}$ \\
\hline
\end{tabular}

Controlled Trial.-In view of the definite nature of the patients' response when it occurred in the pilot study, sequential analysis was considered suitable for assessment of the results. A statistically significant result was obtained at the one-week follow-up after 19 pairs had been assessed. The 20th pair had at that time been injected, and is represented by the point outside the significance limits in Fig. 2. One pair showed a preference for silicone, 10 for saline, and nine showed no

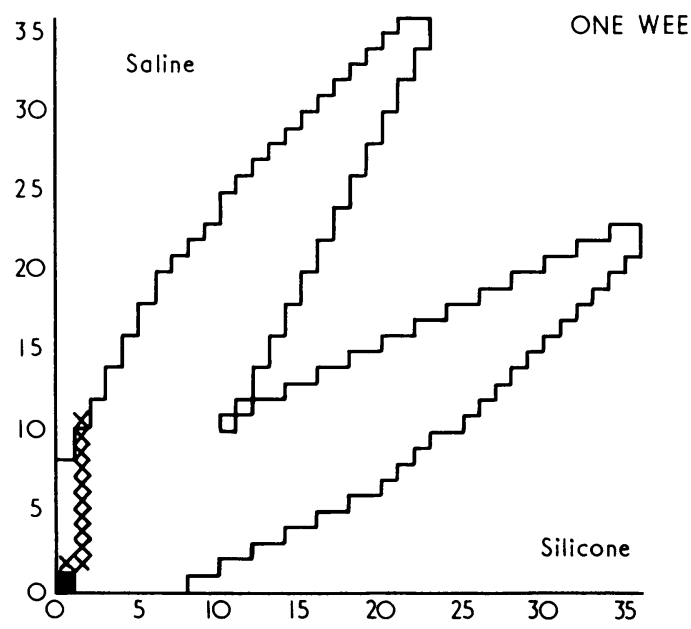

FIG. 2-Sequential analysis one week after treatment with saline and silicone. 
preference. Preference for one substance over another can be obtained in two ways, either improvement with one or deterioration with the other. Four patients showed greater improvement with saline and five deterioration with silicone. Three patients showed a synovial reaction to silicone, and in one case this was so severe that admission to hospital was required for control of pain. Joint aspiration was attempted, but no fluid was withdrawn, the swelling comprising thick, boggy synovium only. The results at one month (Fig. 3) failed to reach the agreed

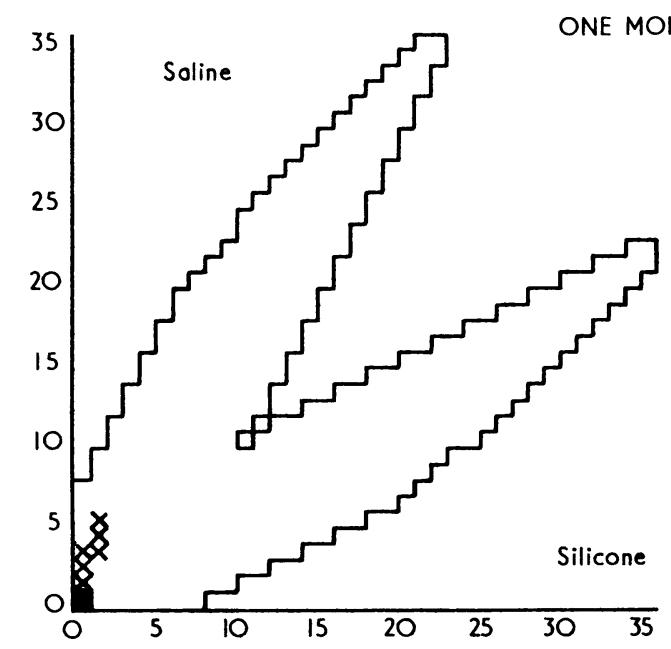

FIG. 3-Sequential analysis one month after treatment with saline and silicone.

level of statistical significance. Five patients expressed a preference for saline, one for silicone, and 14 expressed no preference. The one silicone preference was in a different patient from the one who expressed preference at one week. Though the trend was still towards saline the differences between the injected joints was decreasing and more closely approximating to the preinjection state.

Stiffness.-Objective stiffness measured by the knee arthrograph showed no significant difference in the effect on torque between saline and silicone. Serial readings were taken from a patient admitted to hospital for study of the effect of injection of the two substances (Fig. 4). It shows that admission to hospital itself has a marked effect in reducing joint stiffness and that there was no difference in the effect of the injections.

\section{ANIMAL STUDIES}

In none of the experimental animals was there any evidence of interference with the clearance of radioactive sodium ${ }^{131} \mathrm{I}$ from

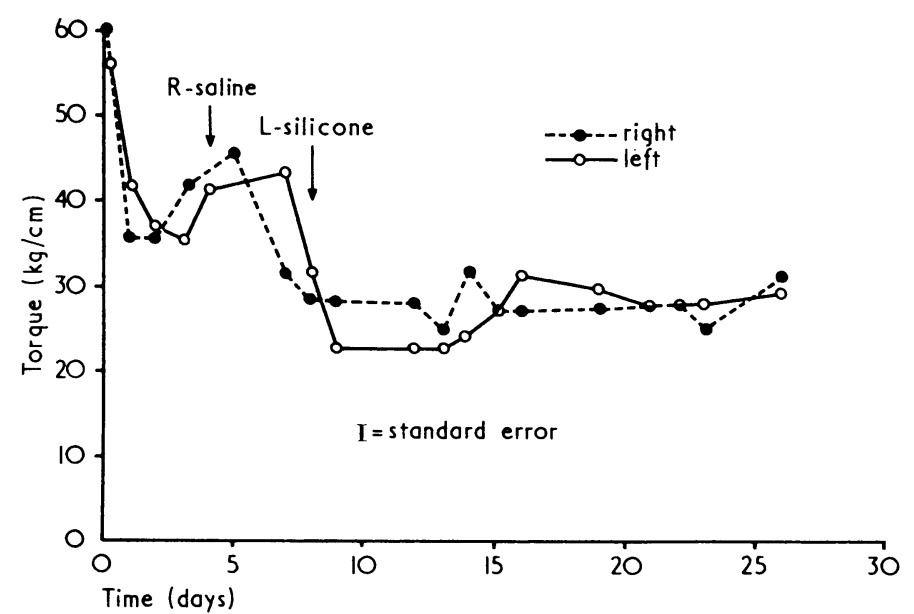

FIG. 4-Stiffness of knees in a patient in hospital. His right knee was injected with $10 \mathrm{ml}$ of saline and the left knee with $10 \mathrm{ml}$ of silicone. the joint compared with the pre-experimental levels or with the contralateral knee, indicating that small molecular clearance and blood flow to the joint was undisturbed. However, with iodinated human serum albumin a clearance pattern was reduced for a period of three to four days following the injection of a single dose of $1.5 \mathrm{ml}$ of silicone 300 , indicating a failure of large molecular clearance from the $j$ jint, though there was no macroscopic evidence of the presence of silicone within the joint in either of the animals killed on the second or fourth postoperative day. In the animal killed 24 hours after the injection of silicone 300 a trace of silicone 300 was discernible. All animals were examined for any histological abnormality in the synovial membrane, regional lymph nodes, kidneys, spleen, liver, and lungs, and there was no macroscopic or microscopical evidence of any abnormality in these tissues, either in the animals killed during the first few days after the experiment or in the long-term survivals. It was, of course, not possible to stain specifically for the presence of silicone.

With regard to the experimental defects produced in the articular cartilage there was no evidence of any accelcration in the healing of the articular cartilage defect in the knees which had been injected with silicone 300 as compared with the contralateral knee of the same experimental animal. In the experimental animals killed at two, three, and five weeks postoperatively the silicone-injected knee showed less evidence of regeneration of articular cartilage as compared with the contralateral knee.

\section{Discussion}

There is evidence that the lubrication mechanism is impaired in osteoarthrotic joints (Walker et al., 1970), and it might be expected that, whatever the cause of the degeneration, improved lubrication would prove beneficial to the joint. Helal and Karadi (1968) reported benefit with silicone in osteoarthrotic joints and rheumatoid knees which were ciry and creaky. At the Middlesex Hospital (Corbett et al., 1970) it was shown that silicone was no better than hydrocortisone acetate injected intra-aricularly. Helal (1970), however, felt this comparison did not invalidate silic one, since hydrocortisone is effective in the treatment of joint disease. This is a reasonable criticism since some of the Middlesex patients had rheumatoid arthritis, which is known to benefit from intra-articular hydrocortisone (Chandler and Wright, 1958).

The present controlled trial gives no support to the use of silicone as an artificial lubricant. Saline gave significantly better results on sequential analysis. It is interesting that the results of the pilot study were encouraging, whereas the controlled trial showed silicone to have at best a placebo effect, with a small risk of quite severe synovial reaction. Placebo reaction is a well-recognized phenomenon in osteoarthrosis, particularly where intra-articular therapy is used (Shah and Wright, 1967). Moreover, objective measurement of knee stiffness with an arthrograph showed that admission to hospital itself produces marked diminution of torque recorded on passive rotation of the knee. Adverse reactions to silicone are not common, but were observed in three of these patients. Similar reactions have been observed previously (Golding, personal communication).

In the rabbit there is no evidence that silicone 300 remains within the articular cavity for a period exceeding 48 hours, and there would appear to be some obstruction to lymphatic outflow as indicated by the failure of clearance of iodinated human serum albumin for a period as long as three to four days after the injection of silicone, and this itself may explain the persistence of an excess of fluid found in some human joints after the injection of silicone. Nor was there any evidence that silicone 300 accelerated the healing of experimentally produced cartilaginous defects in healthy rabbits whose joints were not the site of degenerative disease.

During the period of study the group was grateful for grants from the Arthritis and Rheumatism Council, Reckitt \& Colman, and the 
Leeds Regional Hospital Board. We appreciated the help given by Sister Cox.

\section{References}

Barnett, C. H., and Cobbold, A. F. (1962). Fournal of Bone and foint Surgery, 44B, 662 .

Chandler, G. N., and Wright, V. (1958). Lancet, 2, 659.

Charnley, J. (1960). Triangle, 4, 175.

Corbett, M., Seifert, M. H., Hacking, C., and Webb, S. (1970). British Medical fournal, 1, 24.

Dintenfass, L. (1963). Journal of Bone and foint Surgery, 45A, 1241.

Dowson, D., Longfield, M. D., Walker, P. S., and Wright, V. (1968). Proceedings of the Institution of Mechanical Engineers, 182, 3N, 70.
Goddard, R., Dowson, D., Longfield, M. D., and Wright, V. (1969). In Lubrication and Wear in foints, ed. V. Wright, p. 134. Sector Press. Helal, B. (1970). British Medical fournal, i, 50

Helal, B., and Karadi, B. S. (1968). Annals of Physical Medicine, 9, 334.

Jacobsen, M. (1965). British fournal of Psychiatry, 111, 545.

McCutchen, C. W. (1959). Nature, 184, 1284.

Maroudas, A. (1967). Proceedings of the Institution of Mechanical Engineers, $181,3 \mathrm{~J}, 122$.

Nuki, G., Ferguson, J., Boyle, J. A., and Boddy, K. (1969). Nature, 224, 1118 .

Seller, P. C., Dowson, D., Longfield, M. D., and Wright, V. (1969). In

Lubrication and Wear in foints, ed. V. Wright, p. 142. Sector Press.

Shah, K. D., and Wright, V. (1967). Annals of the Rheumatic Diseases, 26, 316.

Tanner, R. I. (1966). Physics in Medicine and Biology, 11, 119.

\section{Smoking, Chronic Bronchitis, and Lung Cancer}

\section{J. RIMINGTON}

British Medical fournal, 1971, 2, 373-375

\section{Summary}

A follow-up was carried out on 21,579 male mass radiography volunteers aged at least 40 who had been the subject of an earlier investigation in which their smoking habits and sputum production were recorded and the prevalence of lung cancer was determined after chest $x$-ray examination. During the follow-up period, which was a minimum of 36 months and a maximum of 56 months, 64 new cases of lung cancer were identified by cross checking records with the registers of the regional cancer registration bureau. A significantly higher incidence of lung cancer was found in those with chronic bronchitis than in those without this disease. In the smoking categories, cigarette smokers with chronic bronchitis had a higher incidence than those without it, and this relationship was maintained irrespective of age and amount smoked. It is concluded that persons who smoke run a higher risk of chronic bronchitis than non-smokers and those who develop bronchitis run a higher risk of developing lung cancer.

\section{Introduction}

An earlier article (Rimington, 1968a) described how, during 1964 and 1965, the smoking habits and sputum histories of 21,579 male mass radiography examinees were taken before $x$-ray examination, the object being to find and compare the lung cancer rates of those reporting and of those not reporting sputum on most days for at least five years.

Some details of the article will provide continuity with the present study:

The examinees, who came from the part of Cheshire within the Manchester Hospital Region, were volunteers, either from industry or general public and were aged at least 40 . Their smoking habits were similar to those found in a nationwide study by Todd (1966) except for a moderate bias to pipe smokers and non-smokers. Twelve per cent. $(2,716)$ reported sputum on most days for at least five years and there was a marked gradient in the percentage reporting this with increasing cigarette consumption. Thirty-three lung cancers were found, all in past or present smokers. Irrespective of the smoking category, the rates of lung cancer were much higher in those reporting than in those not reporting daily sputum

\section{St. Thomas' Hospital, Stockport SK3 8BL}

J. RIMINGTON, M.D., Medical Director, Mass Radiography ServiceSouthern Division, Manchester Regional Hospital Board for a minimum of five years. Cigarette smokers in these two groups had rates of 5.09 and $1.30 / 1,000$ respectively, and this difference was found to be statistically significant $(P<0.01)$. A similar relationship was maintained irrespective of the amount smoked. Moreover, the lung cancer rates for histologically proved cancers maintained the same relationship.

It was considered that the data were reliable and that the selection of a minimum period of five years for the duration of the sputum production made it unlikely that lung cancer could be the cause of the sputum. Furthermore, it was shown later (Rimington, 1968b) that differences in the age distribution of the volunteers did not account for the differences in prevalence of lung cancer between those reporting and those not reporting daily sputum for a minimum of five years.

It was concluded that the study, taken in conjunction with evidence of other investigations using data derived by different selective processes, confirmed a positive association between chronic bronchitis, as defined on the basis of persistent sputum production for a number of years in the absence of other causative disease, and lung cancer.

The present article gives the results of a follow-up of the original volunteers with particular regard to the lung cancer incidence among those with and those without chronic bronchitis.

\section{Methods}

The identification of new cases of lung cancer arising in the volunteers during the years subsequent to the initial examinations was made possible by the co-operation of the director and staff of the Manchester Regional Cancer Registration Bureau. Cases of malignancy are reported to the bureau by doctors and hospital authorities and, in addition, by the General Register Office when a death certificate refers to malignant disease and the deceased lived in the Manchester Regional Hospital Board's area. So far as the latter category is concerned, the bureau obtains more detailed information from local sources and registers such cases under the year in which the disease was first brought to light.

The volunteers' records were checked against each year's registrations from 1964 to, and including, 1968. The minimum and maximum period of follow-up was 36 and 56 months respectively. A year's registrations were not checked until at least 18 months had passed after the end of the particular year, and this delay meant that most of the late notifications via the General Register Office had been included on the registers because lung cancer, in the absence of treatment, is usually fatal within that period. 